\title{
Research Square \\ Generation of murine sympathoadrenergic progenitor-like cells from embryonic stem cells
}

Shobhit Saxena ( $\sim$ shobhit.saxena@med.lu.se)

Department of Molecular Medicine and Gene Therapy, Lund University

Christian Beltinger

University Medical Center Ulm

\section{Method Article}

Keywords: Neural crest stem cells, sympathoadrenergic progenitors, embryonic stem cells, CD57, GD2, flow cytometry

Posted Date: September 14th, 2015

DOI: https://doi.org/10.1038/protex.2015.083

License: (1) This work is licensed under a Creative Commons Attribution 4.0 International License. Read Full License 


\section{Abstract}

Sympathoadrenergic progenitor cells $\backslash$ (SAPs) of the peripheral nervous system $\backslash$ (PNS) are important for normal development of the sympathetic PNS. SAPs are also thought to be the cell of origin of neuroblastoma, a sympathetic PNS-related childhood tumor. However, it remains difficult to isolate sufficient numbers of SAPs. This protocol describes methodology for the generation of SAPs by differentiating murine embryonic stem cells $\backslash($ ESCs). These advances in SAP generation may facilitate investigations about the normal development and malignant transformation of the sympathetic PNS.

\section{Introduction}

Peripheral sympathoadrenergic cells develop from neural crest cells. An important pathology of the sympathetic peripheral nervous system is neuroblastoma $\backslash(\mathrm{NB})$, where amplification of MYCN is strongly associated with poor prognosis ख(1). Transgenic mice overexpressing human MYCN under the control of the rat TH promoter develop NB \(2). Data from this mouse model point to SAPs as putative cells of origin of NB \(2-5), a notion supported by recent findings of cooperation between MYCN and NBassociated ALK mutant in chick SAPs $\backslash(6)$, zebra fish $\backslash(7)$, and mice $\backslash(8)$. Experimental access to NCSCs and SAPs is crucial for investigating normal as well as aberrant development of the sympathetic PNS. However, derivation of NCSCs and SAPs from ES cells and peripheral tissue is complicated by cellular heterogeneity and low yield. In this methodology we provide step-by-step description to obtain ESCderived NCSCs and SAP-like cells.

\section{Reagents}

${ }^{\star *}$ Culture medium for mouse embryonic stem cells: ${ }^{*}$ DMEM containing 15\% ES-grade FBS, 2 mM LGlutamine, $0.1 \mathrm{mM}$ beta-mercaptoethanol, $0.1 \mathrm{mM}$ non-essential amino acids, $1 \times$ penicillin-streptomycin,

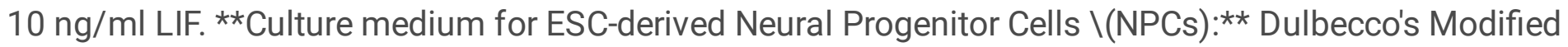
Eagle Medium:Ham's F-12 supplemented with $5 \mu \mathrm{g} / \mathrm{ml}$ insulin, $50 \mu \mathrm{g} / \mathrm{ml}$ transferrin, $30 \mathrm{nM}$ selenium and $5 \mu \mathrm{g} / \mathrm{ml}$ fibronectin. ${ }^{* *}$ Culture medium for neural crest stem cells: ${ }^{* \star}$ 5:3 DMEM low-glucose:neurobasal medium supplemented with $20 \mathrm{ng} / \mathrm{ml} \mathrm{bFGF,} 20 \mathrm{ng} / \mathrm{ml}$ IGF-1, 1\% N2 supplement, 2\% B27 supplement, 35 $\mathrm{ng} / \mathrm{ml}$ retinoic acid, $50 \mu \mathrm{M} \beta$-mercaptoethanol and 15\% chicken embryonic extract.

\section{Equipment}

Dissecting microscope Table top centrifuge $60 \times 15 \mathrm{~mm}$ polystyrene tissue culture dishes 24 well tissue culture plates $5 \mathrm{ml}$ polypropylene round bottom tubes $15 \mathrm{ml}$ polystyrene conical tubes $50 \mathrm{ml}$ polypropylene conical tubes Tissue culture equipment Incubator at $37^{\circ} \mathrm{C}$ with $95 \%$ air and $5 \% \mathrm{CO} 2$ Laminar flow hood or biological safety cabinet Hypoxia chamber

\section{Procedure}


**Mouse Embryonic Stem Cell Culture:** The murine embryonic stem cell $\backslash(\mathrm{mESC})$ line D3 was cultivated on mitotically inactivated primary mouse embryonic fibroblasts $\backslash(\mathrm{MEFs})$. **Embryoid body formation:** About 75 drops of ES medium containing various numbers of ES cells were placed on the lids of $10 \mathrm{~cm}$ petri dishes filled with phosphate-buffered saline \(PBS) and were cultivated as hanging drops for 2 days. EB aggregates were then transferred from the hanging drops into $6 \mathrm{~cm}$ bacteriological petri dishes and were further cultivated for 5 days in suspension. ${ }^{*}$ Generation of ESC-derived Neural Progenitor Cells $\backslash$ (NPCs):** Embryoid bodies $\backslash($ EBs) generated from mESCs by the hanging drop method were plated in Iscove's Modified Dulbecco's Medium containing 10\% FCS on $0.1 \%$ gelatin-coated dishes. After 1 day, medium was replaced with Dulbecco's Modified Eagle Medium:Ham's F-12 \(DMEM/F-12) supplemented with $5 \mu \mathrm{g} / \mathrm{ml}$ insulin, $50 \mu \mathrm{g} / \mathrm{ml}$ transferrin, $30 \mathrm{nM}$ selenium and $5 \mu \mathrm{g} / \mathrm{ml}$ fibronectin. Cells were cultured at $37^{\circ} \mathrm{C}$ and $5 \%$ CO2 for 7 days, generating NPCs. ${ }^{\star \star}$ Enrichment of NCSCs from NPCs with CD 57 expression sorting:** Dissociated NPCs were plated on poly-D-lysine/fibronectin $\backslash$ (both at $150 \mu \mathrm{g} / \mathrm{ml}$ ) coated culture dishes and cultured in NCSC medium, consisting of 5:3 DMEM low-glucose:neurobasal medium supplemented with $20 \mathrm{ng} / \mathrm{ml} \mathrm{bFGF,} 20 \mathrm{ng} / \mathrm{ml}$ IGF-1, 1\% N2 supplement, $2 \%$ B27 supplement, $35 \mathrm{ng} / \mathrm{ml}$ retinoic acid, $50 \mu \mathrm{M} \beta$-mercaptoethanol and 15\% chicken embryonic extract. The cells were cultured for 7 days in a hypoxia chamber adjusted to $3 \%$ oxygen. FACS sorting of low-enriched NCSC-like population for expression of CD57 generated higher-enriched NCSC-like cells. CD57 antibody $\backslash$ (clone NK1, Abcam, Cambridge, UK) was used for FACS sorting. **Higher Enrichment of SAP-like Cells by Sorting for Expression of GD2:** Low-enriched NCSC-like population were FACS-sorted for GD2 expression to generate highly-enriched SAP-like cells. GD2 antibody \(Clone 14.G2a, BD Biosciences) was used to stain the cells for $30 \mathrm{~min}$, followed by FACS sorting.

\section{Timing}

**Approximate time required for the whole procedure: 26 days** 4-5 days: Regular time required for embryonic stem cell culture until the ES colonies remain undifferentiated. 7 days: embryoid body generation as hanging drops. 7 days: generation of neural progenitors from embryoid bodies. 7 days: generation of neural crest stem cells from NPCs.

\section{Anticipated Results}

Enrichment of CD57 expressing NCSC: FACS sorting enables to sort out NCSCs enriched for the expression of CD57. Around 20-25\% of ES-derived NCSCs express CD57. Enrichment of GD2 expressing SAP-like cells: FACS sorting enables the analysis of GD2 expressing SAP-like cells. Around $4 \%$ of ESderived differentiated NCSCs express GD2, a marker for SAP-like cells.

\section{References}

1. Brodeur, G. M., Seeger, R. C., Schwab, M., Varmus, H. E. \& Bishop, J. M. Amplification of N-myc in untreated human neuroblastomas correlates with advanced disease stage. Science $\backslash($ New York, N.Y.) 224, 1121-1124 \(1984). 2. Weiss, W. A., Aldape, K., Mohapatra, G., Feuerstein, B. G. \& Bishop, J. M. Targeted 
expression of MYCN causes neuroblastoma in transgenic mice. The EMBO journal 16, 2985-2995, doi:10.1093/emboj/16.11.2985 \(1997). 3. Weiss, W. A., Godfrey, T., Francisco, C. \& Bishop, J. M. Genome-wide screen for allelic imbalance in a mouse model for neuroblastoma. Cancer research 60, 2483-2487 \(2000). 4. Hansford, L. M. et al. Mechanisms of embryonal tumor initiation: distinct roles for MycN expression and MYCN amplification. Proceedings of the National Academy of Sciences of the United States of America 101, 12664-12669, doi:10.1073/pnas.0401083101 \(2004). 5. Alam, G. et al. MYCN promotes the expansion of Phox2B-positive neuronal progenitors to drive neuroblastoma development. The American journal of pathology 175, 856-866, doi:10.2353/ajpath.2009.090019 \ (2009). 6. Reiff, T. et al. Midkine and Alk signaling in sympathetic neuron proliferation and neuroblastoma predisposition. Development $\backslash$ (Cambridge, England) 138, 4699-4708, doi:10.1242/dev.072157 \(2011). 7. Zhu, S. et al. Activated ALK collaborates with MYCN in neuroblastoma pathogenesis. Cancer cell 21, 362373, doi:10.1016/j.ccr.2012.02.010 \(2012). 8. Berry, T. et al. The ALK\(F1174L) mutation potentiates the oncogenic activity of MYCN in neuroblastoma. Cancer cell 22, 117-130, doi:10.1016/j.ccr.2012.06.001। (2012).

\section{Figures}



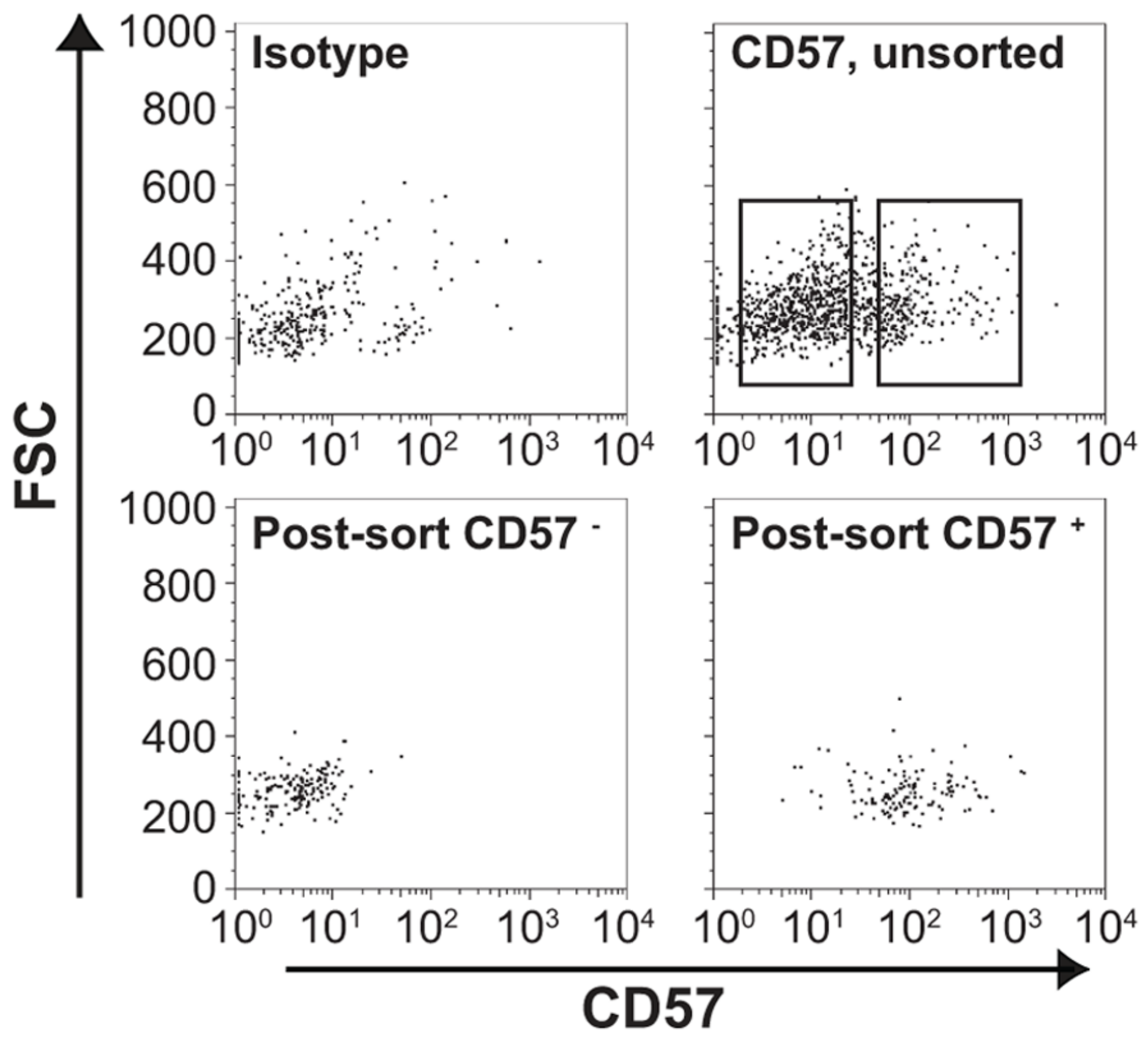

Figure 1

FACS sorting of CD57 expressing NCSCs A subset of low-enriched NCSC-like cells expresses CD57 and can be isolated by FACS. Low-enriched NCSC-like cells were used. Left upper panel shows isotype control, right upper panel unsorted CD57-stained cells and lower panels post-sort plots of the CD57 negative and CD57 positive fractions. 


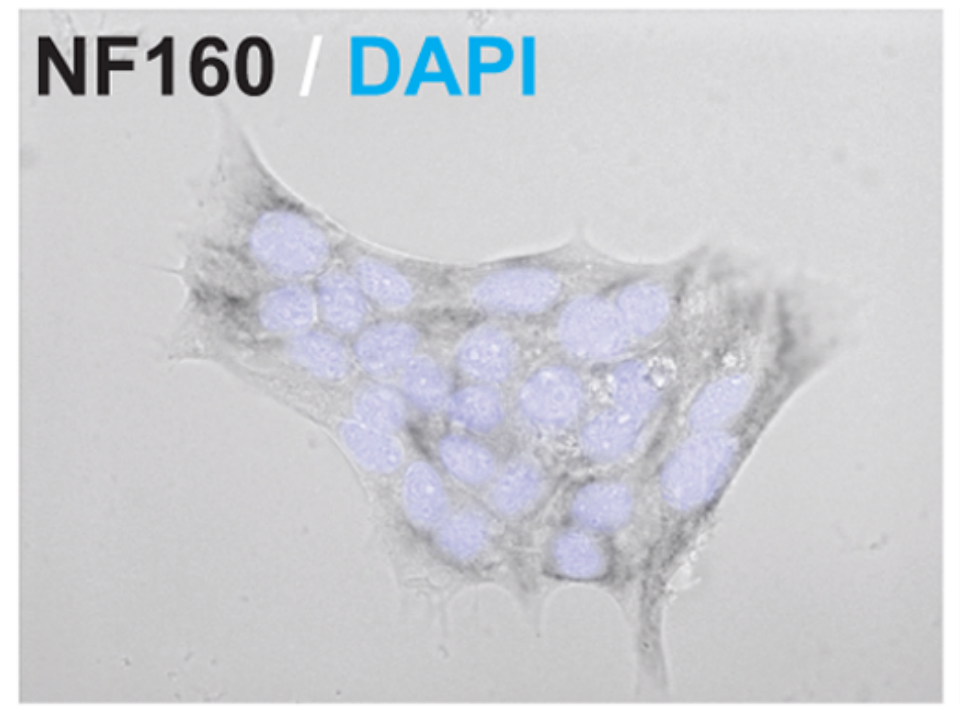

\section{GFAP / DAPI}

\section{SMA / DAPI}

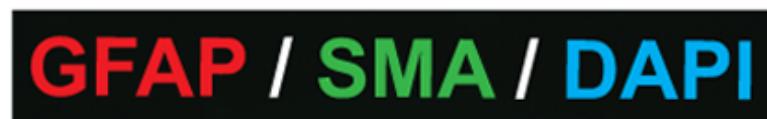

\section{Figure 2}

CD57 expressing NCSCs are tripotent CD57-sorted cells were cultured at clonal density in NCSC medium and the resultant clones were simultaneously stained for NF160, GFAP, SMA and DAPI. A trilineage clone is shown. Scale bar equals $100 \mu \mathrm{m}$. 


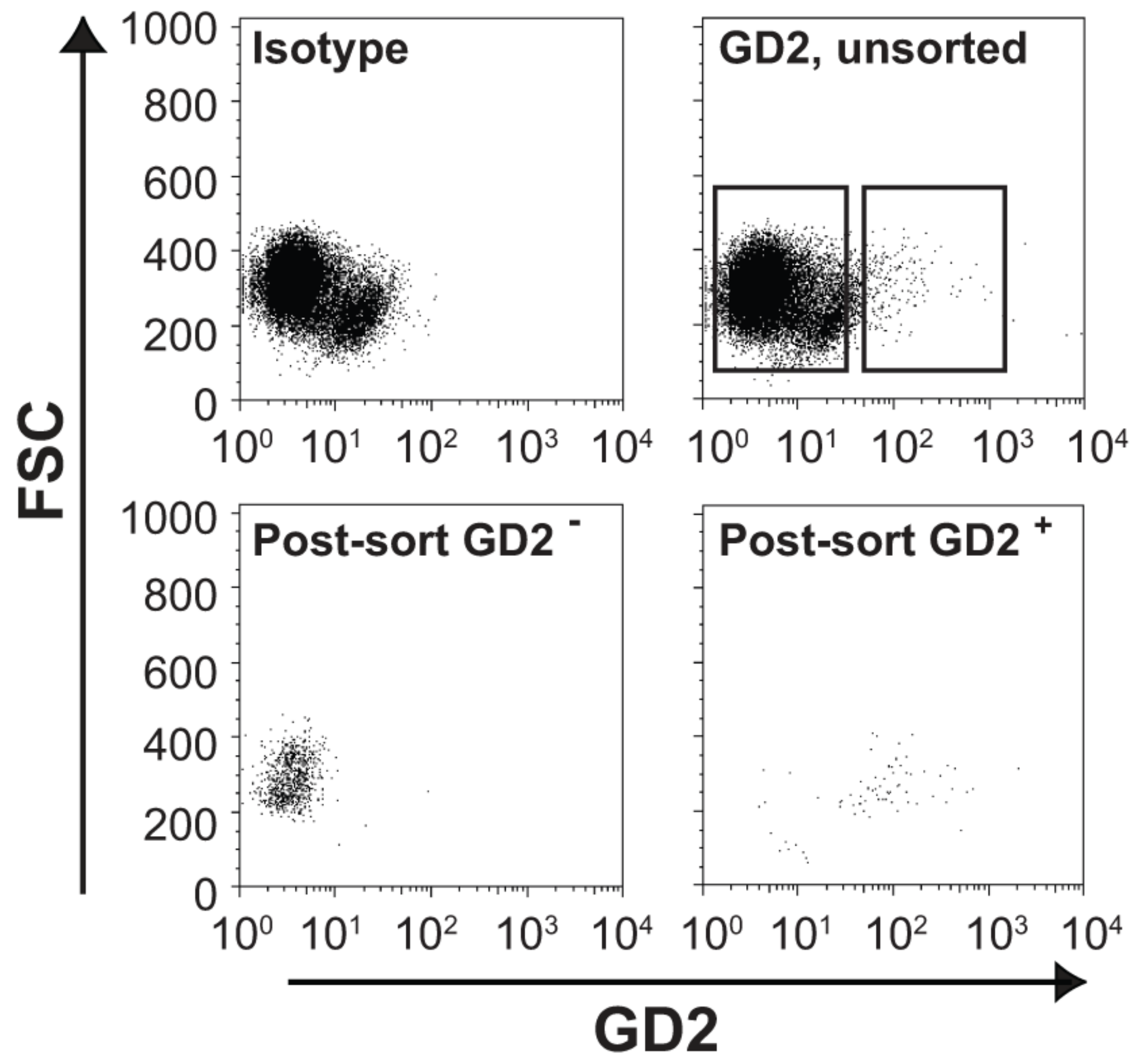

Figure 3

FACS sorting of GD2 expressing SAP-like cells A subset of the low-enrichment NCSC-like population expresses GD2. ES-derived low-enriched NCSC cultures were sorted into GD2 negative and GD2 positive fractions. Left upper panel shows the isotype control, right upper panel the GD2-stained population and the lower panels post-sort plots of the GD2 negative and GD2 positive fractions. 

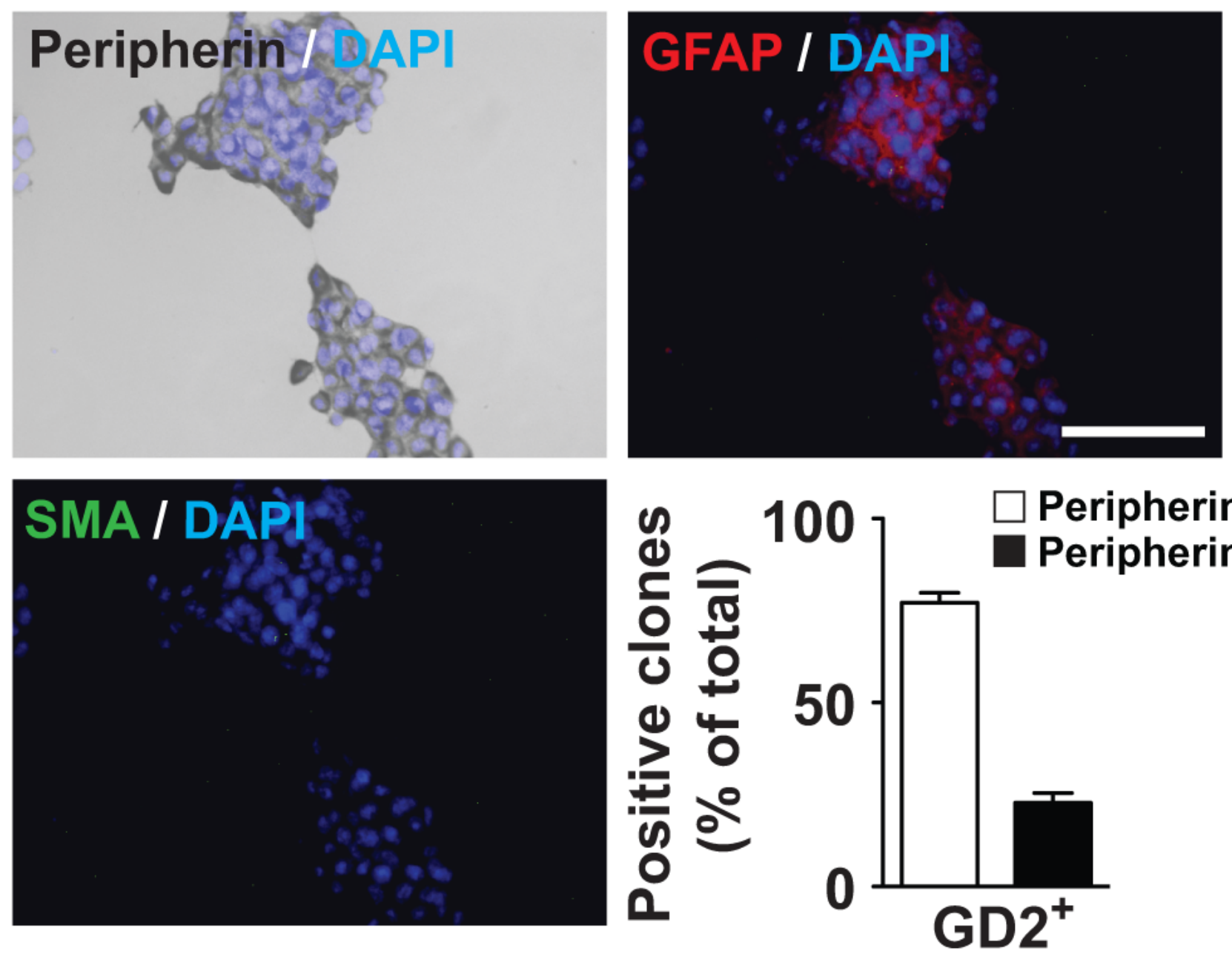

Figure 4

The large majority of GD2+ cells are bilineage SAP-like cells GD2-sorted cells were cultured at clonal density for $7 \mathrm{~d}$ in NCSC medium and resultant clones were simultaneously stained for peripherin, GFAP and SMA. A peripherin+GFAP+ clone is shown, scale bar equals $100 \mu \mathrm{m}$. Quantification of the clones is shown in the histogram, the means of three independent experiments (with a total of 219 clones) are depicted. 